OPEN ACCESS

Edited and reviewed by: Ulrich M. Zanger,

Dr. Margarete Fischer-Bosch Institut für Klinische Pharmakologie (IKP),

Germany

${ }^{*}$ Correspondence: Gilles Truan

gilles.truan@insa-toulouse.fr Michel Kranendonk michel.kranendonk@nms.unl.pt

${ }^{\dagger}$ These authors have contributed equally to this work.

Specialty section: This article was submitted to Pharmacogenetics and

Pharmacogenomics,

a section of the journal Frontiers in Pharmacology

Received: 13 February 2018 Accepted: 16 February 2018 Published: 19 March 2018

Citation:

Campelo D, Lautier T, Urban $P$, Esteves F, Bozonnet S, Truan $G$ and Kranendonk M (2018) Correction: The Hinge Segment of Human NADPH-Cytochrome P450 Reductase

in Conformational Switching: The Critical Role of lonic Strength. Front. Pharmacol. 9:175. doi: 10.3389/fphar.2018.00175

\section{Correction: The Hinge Segment of Human NADPH-Cytochrome P450 Reductase in Conformational Switching: The Critical Role of Ionic Strength}

\author{
Diana Campelo ${ }^{1 \dagger}$, Thomas Lautier ${ }^{2 \dagger}$, Philippe Urban ${ }^{2}$, Francisco Esteves ${ }^{1}$, \\ Sophie Bozonnet ${ }^{2}$, Gilles Truan ${ }^{2 *}$ and Michel Kranendonk ${ }^{1 *}$ \\ ${ }^{1}$ Center for Toxicogenomics and Human Health (ToxOmics), Genetics, Oncology and Human Toxicology, NOVA Medical \\ School, Faculdade de Ciências Médicas, Universidade Nova de Lisboa, Lisboa, Portugal, ${ }^{2}$ LISBP, Université de Toulouse, \\ CNRS, INRA, INSA, Toulouse, France
}

Keywords: diflavin reductase, protein dynamics, multidomain proteins, conformational exchange, electron transfer, protein-protein interaction

\section{A correction on}

The Hinge Segment of Human NADPH-Cytochrome P450 Reductase in Conformational Switching: The Critical Role of Ionic Strength

by Campelo, D., Lautier, T., Urban, P., Esteves, F., Bozonnet, S., Truan, G., et al. (2017). Front. Pharmacol. 8:755. doi: 10.3389/fphar.2017.00755

There is a mistake in the values of the y axis of Figure 1. The correct version of Figure 1 appears below. The authors apologize for the mistake. This error does not change the scientific conclusions of the article in any way.

The original article has been updated.

Conflict of Interest Statement: The authors declare that the research was conducted in the absence of any commercial or financial relationships that could be construed as a potential conflict of interest.

Copyright $\odot 2018$ Campelo, Lautier, Urban, Esteves, Bozonnet, Truan and Kranendonk. This is an open-access article distributed under the terms of the Creative Commons Attribution License (CC BY). The use, distribution or reproduction in other forums is permitted, provided the original author(s) and the copyright owner are credited and that the original publication in this journal is cited, in accordance with accepted academic practice. No use, distribution or reproduction is permitted which does not comply with these terms. 


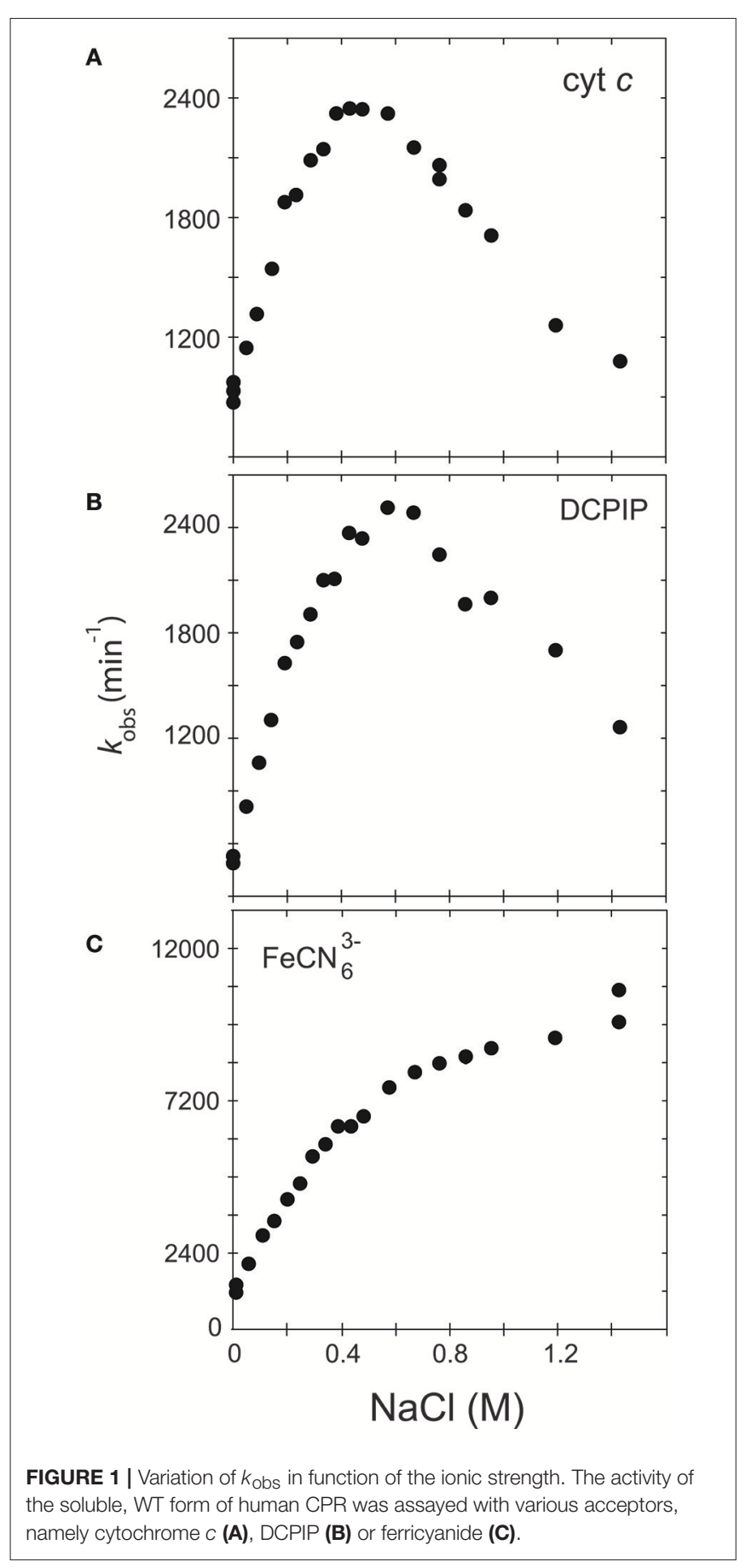

